\title{
Carbon dioxide and water vapour characteristics on the west coast of Arabian Sea during Indian summer monsoon
}

\author{
T Dharmaraj*, M N Patil, R T Waghmare and P Ernest Raj \\ Indian Institute of Tropical Meteorology, Pune 411 008, India. \\ ${ }^{*}$ Corresponding author. e-mail: dharam@tropmet.res.in
}

\begin{abstract}
Carbon dioxide, water vapour, air temperature and wind measurements at $10 \mathrm{~Hz}$ sampling rate were carried out over the coast of Arabian Sea, Goa $\left(15^{\circ} 21^{\prime} \mathrm{N}, 73^{\circ} 51^{\prime} \mathrm{E}\right)$ in India. These observations were collected, in association with the surface layer turbulent parameters for the Arabian Sea Monsoon Experiment (ARMEX). In the summer monsoon period, concentration of $\mathrm{CO}_{2}$ was in the range of $550-790 \mathrm{mg} \mathrm{m}^{-3}$ whereas the water vapour was in the range of $17.5-24.5 \mathrm{~g} \mathrm{~m}^{-3}$. The Fast Fourier Transform (FFT) analysis has been performed on these observations to investigate the spectral behaviour of $\mathrm{CO}_{2}$ and water vapour. The relation between $\mathrm{CO}_{2}$ and water vapour on various atmospheric scales has been proposed. $\mathrm{CO}_{2}$ and water vapour observations confirmed the existence of periodicities of large (11, 8 days), meso (5 days) and micrometeorological (20 min) scales.
\end{abstract}

\section{Introduction}

Carbon dioxide and water vapour in the atmosphere are considered as the green-house gases and responsible for the global warming, hence much attention has been given to its measurement and analysis (Jones et al. 1978; Jones and Smith 1977; Leuning et al. 1982; Ohtaki and Matsui 1982; Ohtaki 1985). Atmospheric $\mathrm{CO}_{2}$ has been rising due to anthropogenic emissions which include fossil fuel combustion, deforestation, etc., contributing to global warming (IPCC 2007). Climate studies show that the global warming can be attributed to increase in atmospheric $\mathrm{CO}_{2}$ that enhances evaporation from oceans which in turn will raise water vapour in the atmosphere. The $\mathrm{CO}_{2}$ measurements over Mauna Loa showed $19.4 \%$ increase in the mean annual concentration from 315.98 parts per million by volume (ppmv) of dry air in 1959 to 377.38 ppmv in 2004 (Bacastow et al. 1985). In the atmospheric boundary layer (ABL), turbulence and diffusion influence the vertical and horizontal distribution of $\mathrm{CO}_{2}$ and water vapour concentration. Increase of water vapour in the lower atmosphere by a few percent can affect the radiation budget as much as doubling $\mathrm{CO}_{2}$, which brings it to the first position among green house gases. The surface $\mathrm{CO}_{2}$ concentration is related with the boundary layer stability. The near surface $\mathrm{CO}_{2}$ shows diurnal variation; day time reduction in $\mathrm{CO}_{2}$ caused by photosynthetic uptake and increased convective turbulent mixing in the surface layer whereas night time amplification of $\mathrm{CO}_{2}$ is due to the respiration and stagnation by a shallow stable ABL. Ocean is normally a sink for $\mathrm{CO}_{2}$ and a source for water vapour, hence variation in these quantities is of interest when wind blows from the sea towards the coast and vice versa. The various studies over Indian oceanic region revealed that the north Indian Ocean is a net sink of atmospheric

Keywords. Carbon dioxide; water vapour; Indian summer monsoon; power spectra. 
$\mathrm{CO}_{2}$ (Takahashi 1989; Louanchi et al. 1996). Overall continental seas are net sinks for atmospheric $\mathrm{CO}_{2}$ although there are strong regional differences in the direction of the air-sea $\mathrm{CO}_{2}$ fluxes, with tropical and subtropical systems acting as sources of $\mathrm{CO}_{2}$ to the atmosphere and mid and high latitude systems acting as sinks for atmospheric $\mathrm{CO}_{2}$ (Borges 2005; Borges et al. 2005; Cai et al. 2006; Chen and Borges 2009). However, near-shore coastal ecosystems are, in general, sources of $\mathrm{CO}_{2}$ to the atmosphere due to the influence of inputs from land (Abil and Borges 2004; Borges 2005; Borges et al. 2005, 2006; Chen and Borges 2009). Tans et al. (1990) found that $\mathrm{CO}_{2}$ in surface water of north Indian Ocean is richer than in the atmosphere and Sarma et al. (1998) also showed that the $\mathrm{CO}_{2}$ concentration is higher in the surface waters than in the atmosphere over the Arabian Sea, except in the southwest monsoon season. Sirignano et al. (2010) observed the annual pattern of the $\mathrm{CO}_{2}$ over the coastal stations (Macehead and Lutjewad) of Europe and showed that concentrations were minimum in the month of February/ March and maximum in August. Unfortunately, no long-term measurements of $\mathrm{CO}_{2}$ are available in the coastal region of India to distinguish seasonal and annual variations in the $\mathrm{CO}_{2}$ balance. Hence, it is of interest to measure and investigate $\mathrm{CO}_{2}$ and water vapour variations near the coast of Arabian Sea during the summer monsoon season. In this paper, $\mathrm{CO}_{2}$ and water vapour mass density observations collected using a fast response open path infrared gas analyzer at Arabian Sea coastal site, Goa, are presented and discussed. The Fast Fourier Transform (FFT) analysis is performed to study the existence of various atmospheric scales. The relationship between $\mathrm{CO}_{2}$ and water vapour has been proposed on the basis of atmospheric scales.

\section{Topography of the site and experiment}

A micrometeorological tower $(9 \mathrm{~m}$ high $)$ was erected on the headland $(58.5 \mathrm{~m}$ asl $)$ in the premises of National Centre for Antarctic and Ocean Research (NCAOR), Vasco da Gama, Goa $\left(15^{\circ} 21^{\prime} \mathrm{N}, 73^{\circ} 51^{\prime} \mathrm{E}\right)$ which is $\sim 25 \mathrm{~m}$ away from the Arabian Sea coast. Figure 1 shows the topography of the site and experiment set-up. A Sonic anemometer (Applied Technology, USA) and $\mathrm{H}_{2} \mathrm{O} / \mathrm{CO}_{2}$ analyzer (LICOR-7500, USA) was installed at $5 \mathrm{~m}$ height to measure the fluctuations of $\mathrm{CO}_{2}$, water vapour, wind components $(u, v$ and $w)$, wind direction and air temperature $(T)$. These observations were sampled at $10 \mathrm{~Hz}$ and were further averaged for 30 minutes to use in the analysis. The NCAOR buildings are $\sim 150 \mathrm{~m}$ away towards the north direction of tower. During monsoon season, forest breeding plants and grass of about 1-1.5 $\mathrm{m}$ height grow over the terrain on NW-NE sector. The experimental site has a large fetch (sea) in the upwind direction. Except wind from NNEESE direction, the wind approaching the coast from all other directions will be from the sea. Wind coming from $\mathrm{N}-\mathrm{ESE}$ direction $\left(0-112^{\circ}\right)$ is taken as a wind from land is shown from wind rose plot (figure 2).

The $\mathrm{CO}_{2} / \mathrm{H}_{2} \mathrm{O}$ analyzer is a high performance, non-dispersive open path instrument used in eddy covariance flux measurements. It uses the principle of absorption of infrared beam (source) by water

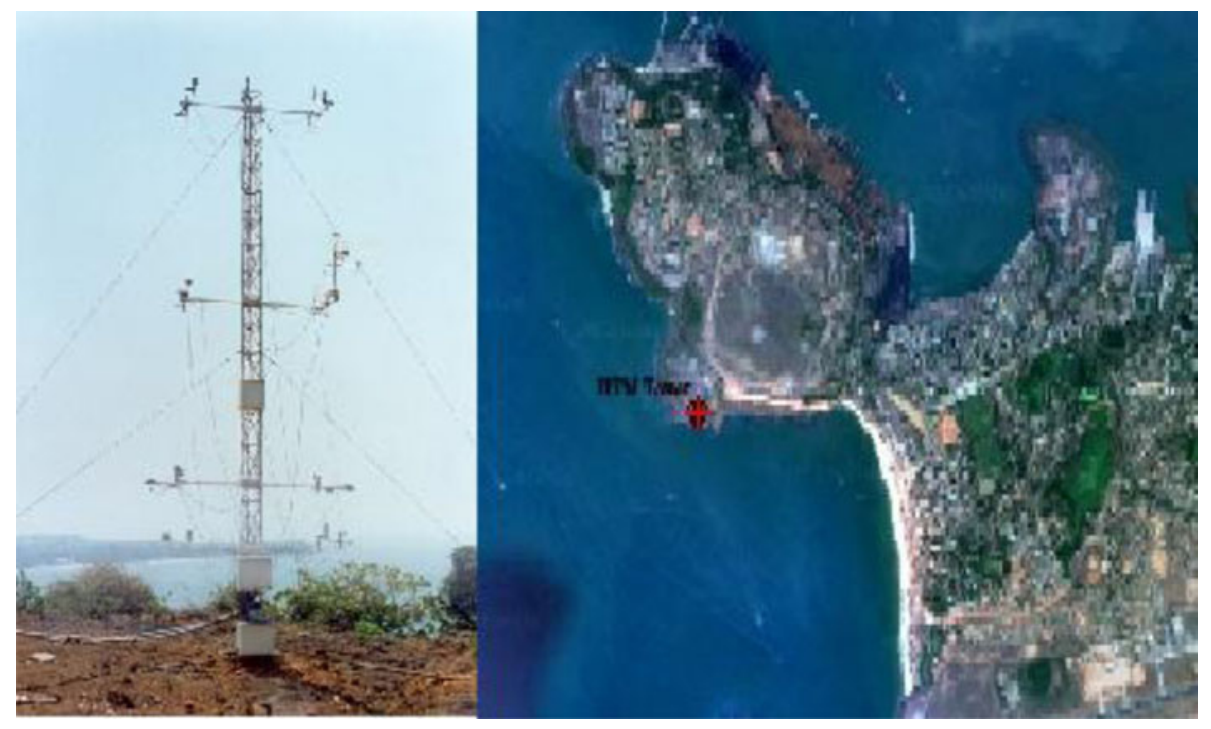

Figure 1. Topography and experimental setup near the observational site. 


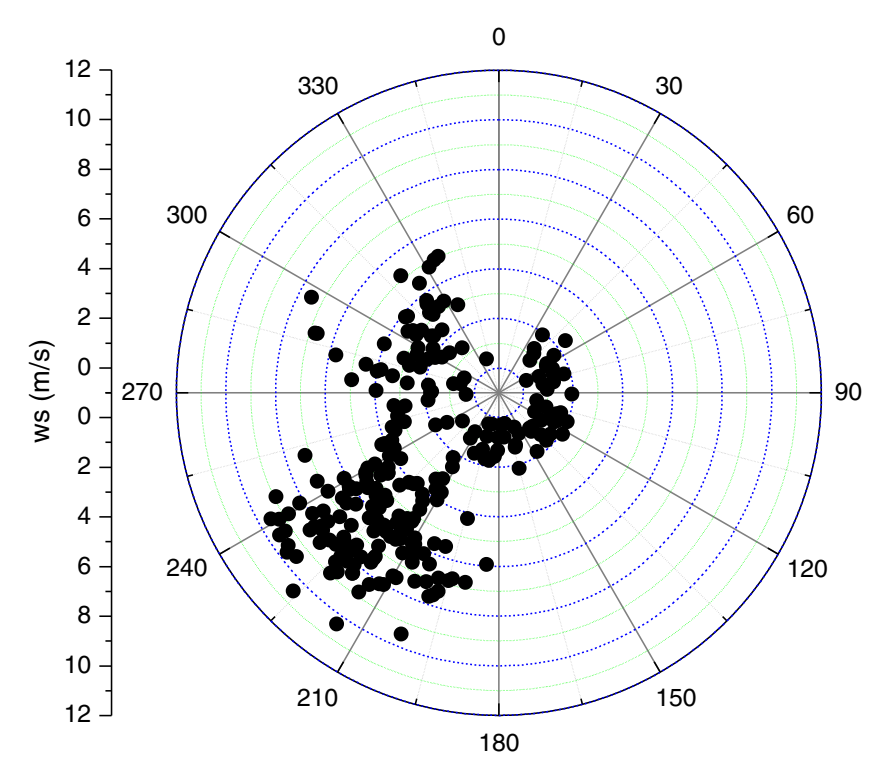

Figure 2. Observed wind rose over the experimental site for July 2-19, 2002.

vapour and $\mathrm{CO}_{2}$ at their absorption wavelengths (2.59 and $4.26 \mu \mathrm{m}$, respectively). Detector is a thermo-electrically cooled lead selenide. Data from LI-7500 was collected through RS232 interface in a $\mathrm{PC}$ at the rate of $10 \mathrm{~Hz}$. Accuracy of the instrument for $\mathrm{CO}_{2}$ is $1 \%$ nominal and $1 \%$ for $\mathrm{H}_{2} \mathrm{O}$. During rain, flying droplets and flakes in the optical path will affect the performance of LI-7500, even if the total light blockage is small enough. Hence the spikes due to rain and other adverse effects were eliminated, in the analysis of the data.

\section{Data analysis}

The $\mathrm{CO}_{2}$, water vapour, temperature, wind speed (u, $v$ and $w$ component) and wind direction were measured at above station. We estimate the Monin-Obukhov length $(L)$ by eddy correlation method using equation (1) to establish the stability regime. To look into the relation of stability with $\mathrm{CO}_{2}$ and water vapour, the entire dataset (four months: July-September) is separated into unstable and stable cases based on non-dimensional Monin-Obukhov length scale $(z / L)$.

$$
\frac{z}{L}=\frac{(g / \theta)\left(\overline{w^{\prime} \theta^{\prime}}\right)}{u_{* / k z}^{3}}
$$

$z$ being the observational height and $L$ the MoninObukhov length. $\overline{w^{\prime} \theta^{\prime}}$ is the surface sensible heat flux and $u_{*}$ is the frictional velocity given by equation (2)

$$
u_{*}=\left[\left(\overline{u^{\prime} w^{\prime}}\right)^{2}+\left(\overline{v^{\prime} w^{\prime}}\right)^{2}\right]^{\frac{1}{4}}
$$

where the primes represent the fluctuations and overbars, the averages over the period long enough to assure stationarity. The $u, v$ and $w$ are the longitudinal, lateral and vertical components of wind respectively. Positive magnitude of $z / L$ indicates stable conditions and vice versa. We observed the following stability regimes for the unstable and stable conditions under different wind conditions.

$$
\begin{aligned}
& \frac{z}{L}=-0.02 \text { to }-1.08 ; \quad u>3 \mathrm{~ms}^{-1}, \\
& \frac{z}{L}=-0.19 \text { to }-2.3 ; \quad u<3 \mathrm{~ms}^{-1}, \\
& \frac{z}{L}=0.03 \text { to } 0.28, \quad u>3 \mathrm{~ms}^{-1}, \\
& \frac{z}{L}=0.03 \text { to } 0.35 ; \quad u<3 \mathrm{~ms}^{-1} .
\end{aligned}
$$

The spectral analysis (16384 point FFT) had been performed for $\mathrm{CO}_{2}$ and water vapour dataset. Halfhourly averaged data of $\mathrm{CO}_{2}$ and water vapour, originally sampled at $0.1 \mathrm{~s}(10 \mathrm{~Hz})$ interval, were used under different stability regime defined above.

\section{Results and discussion}

The observational period was the southwest monsoon season in the year 2002 over India. The fast sampling measurements were discontinued whenever rain episodes occurred. This caused the discontinuity in the dataset. The following subsections describe the micro, meso and synoptic scale behaviour of $\mathrm{CO}_{2}$ and water vapour observations over Goa.

\subsection{Diurnal variation of $\mathrm{CO}_{2}$ and water vapour}

Continuous data of $\mathrm{CO}_{2}$ and water vapour at one minute intervals over 30 minutes duration is shown in figure 3(a). It clearly shows that whenever the magnitude of $\mathrm{CO}_{2}$ increased, the magnitude of water vapour decreased. $\mathrm{CO}_{2}$ varied between 625 and $645 \mathrm{mg} \mathrm{m}^{-3}$ and water vapour from 20.5 to $24 \mathrm{gm} \mathrm{m}^{-3}$. The inverse relation between $\mathrm{CO}_{2}$ and water vapour is also observed in the one-minute sample data (at $0.1 \mathrm{~s}$ rate) as shown in figure $3(\mathrm{~b})$. Daily averaged $\mathrm{CO}_{2}$ and water vapour for the period of 17 July to 15 October 2002 is shown in figure 3(c) to investigate day-to-day variations. 

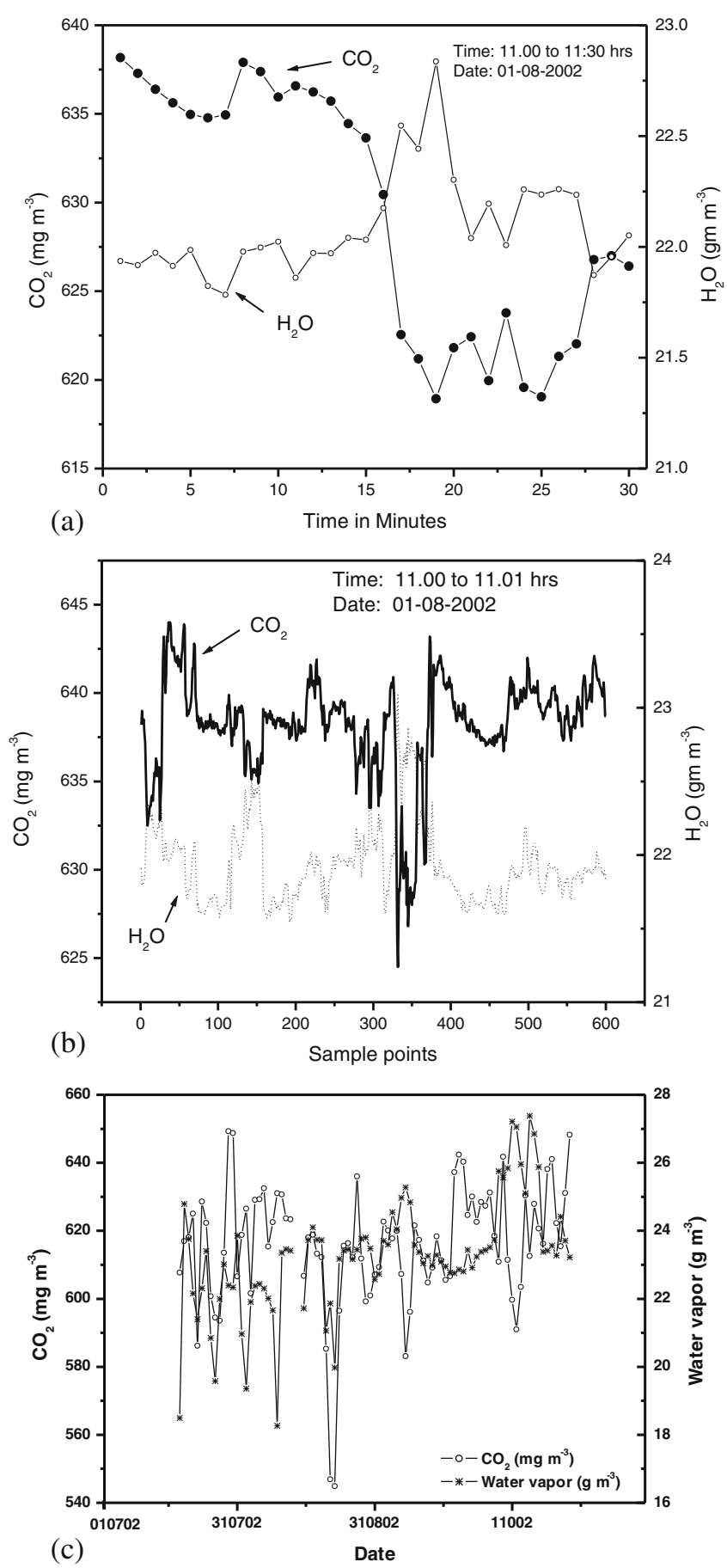

Figure 3. (a) Variation of $\mathrm{CO}_{2}$ and water vapour in $30 \mathrm{~min}$ time duration on 1st August 2002. (b) Variation of $\mathrm{CO}_{2}$ and water vapour in 1 min time duration on 1st August 2002. (c) Daily variation of mean $\mathrm{CO}_{2}$ and water vapour during 17 July-15 October 2002.

During this period (monsoon), $\mathrm{CO}_{2}$ is observed to be between 545 and $650 \mathrm{mg} \mathrm{m}^{-3}$. The observed inverse relation between $\mathrm{CO}_{2}$ and water vapour on smaller time scales is not very evident in dayto-day variations. Sirignano et al. (2010) observed the values of $\mathrm{CO}_{2}$ concentrations over two coastal stations of west Europe (MaceHead and Lutjewad) and the magnitude was ranging from 369-377 ppm (nearly $664.2-678.6 \mathrm{mg} \mathrm{m}^{-3}$ ) for MaceHead and 374-380 ppm (nearly 673.2-684.0 $\mathrm{mg} \mathrm{m}^{-3}$ ) for Lutjewad. Sturm et al. (2005) also reported year-toyear $\mathrm{CO}_{2}$ variation which was in the range of 364$382 \mathrm{ppm}\left(655.2-687.6 \mathrm{mg} \mathrm{m}^{-3}\right)$ for Jungfraujoch, Switzerland and in the range of $362-396 \mathrm{ppm}$ (651.6-712.8 $\mathrm{mg} \mathrm{m}^{-3}$ ) for the station Puy de Dome in France. In this study, the observed magnitude of $\mathrm{CO}_{2}$ concentration (see figure $3 \mathrm{c}$ ) is comparable to the above-reported magnitudes for some stations in Europe. $\mathrm{CO}_{2}$ varied between 550 and $645 \mathrm{mg} \mathrm{m}^{-3}$ and water vapour from 19 to $24 \mathrm{gm} \mathrm{m}^{-3}$ during unstable condition whereas $\mathrm{CO}_{2}$ varied between 585 and $640 \mathrm{mg} \mathrm{m}^{-3}$ and water vapour from 18.5 to $28 \mathrm{gm} \mathrm{m}^{-3}$ during stable condition for the period July to September (figure 4). The inverse relation between $\mathrm{CO}_{2}$ and water vapour is also observed in both unstable and stable conditions as shown in figure 5. The wind speed was ranging between $2-8 \mathrm{~ms}^{-1}$ in unstable and $1-7 \mathrm{~ms}^{-1}$ in stable conditions.

\subsection{Spectrum of $\mathrm{CO}_{2}$ and water vapour}

The spectral analysis (16384 point FFT) has been performed for $\mathrm{CO}_{2}$ and water vapour dataset. Halfhourly data of $\mathrm{CO}_{2}$ and water vapour sampled at $10 \mathrm{~Hz}$ interval were used under different stability conditions defined above as well as under light and moderate wind conditions. When $z / L$ is negative and $U>3 \mathrm{~ms}^{-1}$ (figure 5) the spectrum of $\mathrm{CO}_{2}$ and water vapour in unstable conditions shows a flat region (zero-slope) in the frequency band 0.0101$0.268 \mathrm{~Hz}$ and $0.0033-0.3146 \mathrm{~Hz}$ respectively. Both the spectra show an energy peak at $0.05 \mathrm{~Hz}$ when $U<3 \mathrm{~ms}^{-1}$. The $\mathrm{CO}_{2}$ spectrum also shows an energy peak at $0.003 \mathrm{~Hz}$. The region of zero slope is not prominent in $\mathrm{CO}_{2}$ spectrum for stable case when $U>3 \mathrm{~ms}^{-1}$ as in unstable case. Flat region in the case of water vapour spectrum extends from $0.067 \mathrm{~Hz}$ at the low frequency end to $0.347 \mathrm{~Hz}$. For $U<3 \mathrm{~ms}^{-1}$ the zero-slope in $\mathrm{CO}_{2}$ spectrum extends from 0.00359 to $0.0393 \mathrm{~Hz}$ and water vapour from 0.0031 to $0.0598 \mathrm{~Hz}$. The zero-slope (power law) indicates signature of a matching layer between large scale motion above and a small scale motion below produced by shear stress near the surface (McNaughton and Laubach 2000). In the case of $U>3 \mathrm{~ms}^{-1}$, zero-slope is seen in both stable and unstable conditions of the atmosphere while for $U<3 \mathrm{~ms}^{-1}$, the zero-slope is not present in very unstable atmosphere when free convection prevails. As seen in figure $5(\mathrm{a}-\mathrm{d})$, the spectral peak is well depicted in the high frequency zone under unstable conditions for both light and moderate 

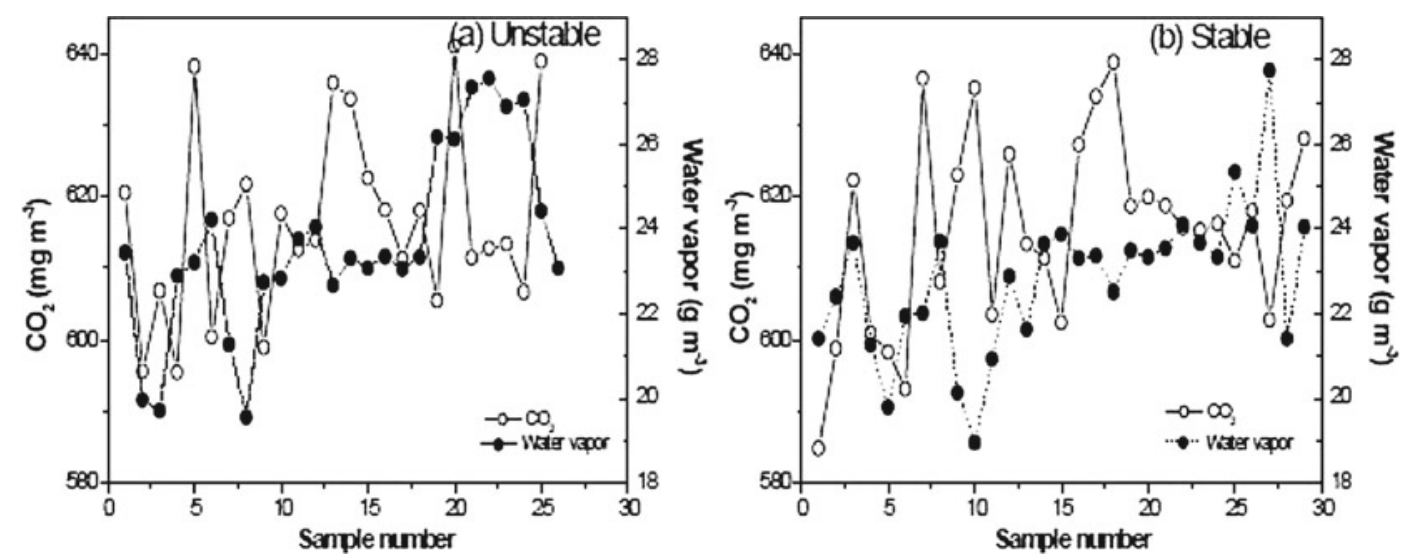

Figure 4. Variation of $\mathrm{CO}_{2}$ and water vapour in stable and unstable conditions during July-September 2002.

Date: $06.08 .2002(1130 \mathrm{hrs})$
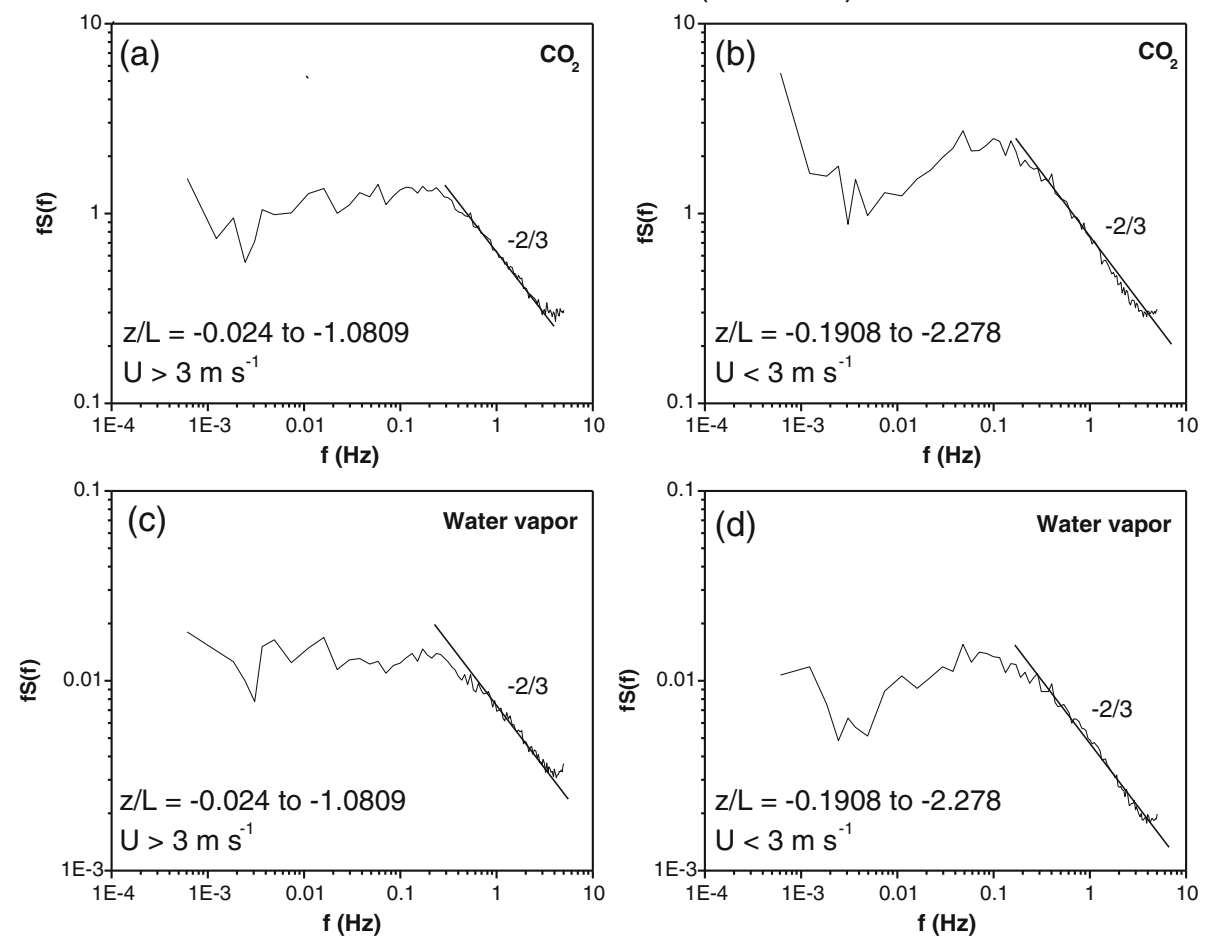

Figure 5. Average power spectrum of $\mathrm{CO}_{2}$ and water vapour in unstable condition for low and high wind speed on 6 August 2002.

wind conditions. This indicates the convective mixing of $\mathrm{CO}_{2}$ and water vapour under unstable conditions. The spectral peak is shifted towards the higher frequency portion in the stable cases in both low and moderate wind conditions (see figure 6). This indicated the suppressed mixing of $\mathrm{CO}_{2}$ and water vapour in both low and moderate wind conditions under stable condition.

\subsection{Composite spectra}

An interesting part of this spectral study is the existence of various periodicities of different scales of atmospheric motion being reflected in the time variations of scalars such as $\mathrm{CO}_{2}$ and water vapour. Figure 7 shows the composite spectrum of $\mathrm{CO}_{2}$ and water vapour depicting large, meso and small scale motion against corresponding time period expressed in 'hours'. It is cumbersome to apply FFT to a fast sampled data acquired at $10 \mathrm{~Hz}$ rate over four-month period due to large number of sampling points and the occasional gaps in the data due to rain and other technical problems. To obtain various periodicities of different scales of atmospheric motion, spectral analysis was performed by averaging the raw data (10 $\mathrm{Hz}$ samples) 
Date:06.08.2002 (2200 hrs)
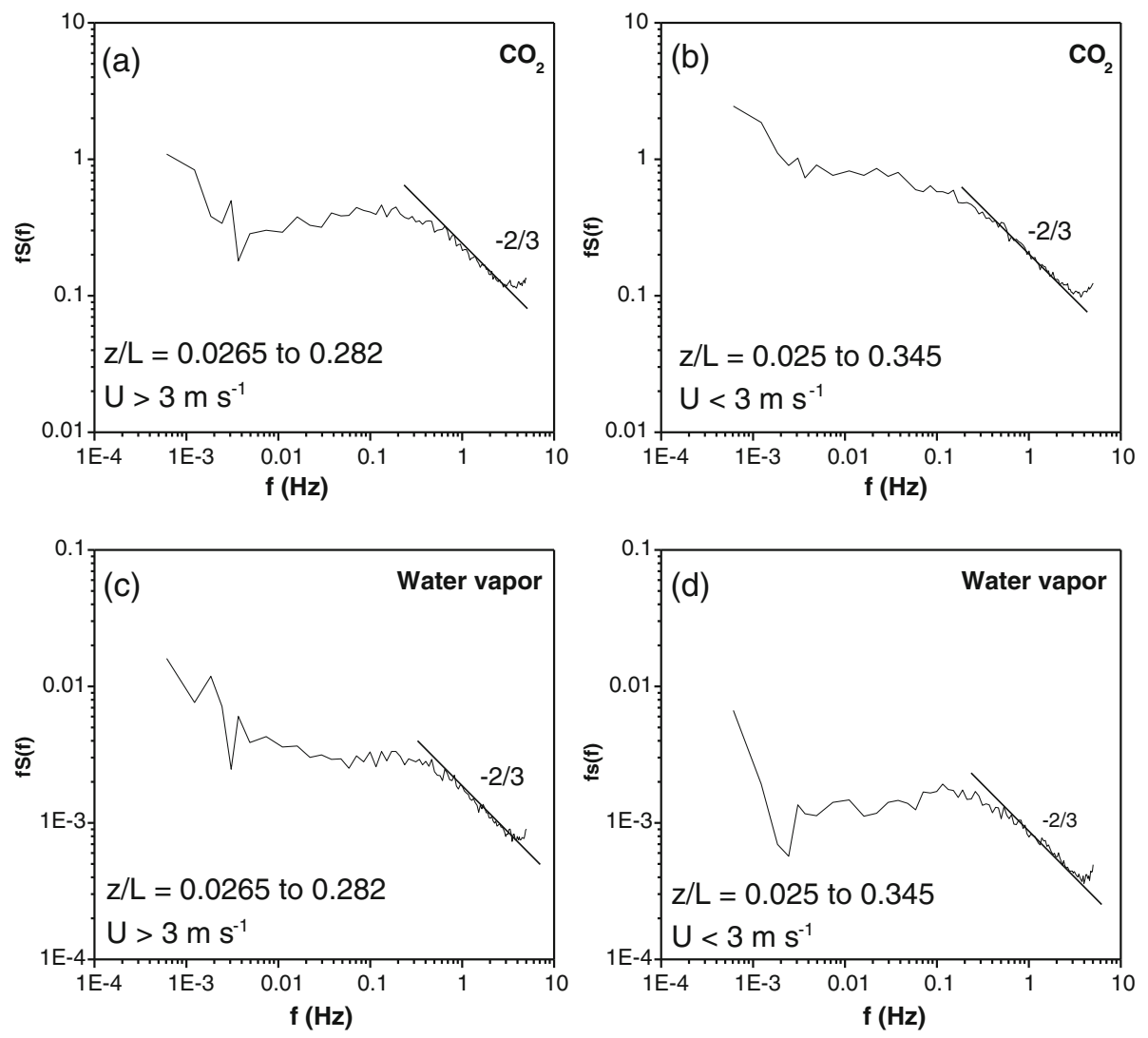

Figure 6. Average power spectrum of $\mathrm{CO}_{2}$ and water vapour in stable condition for low and high wind speed on 6 August 2002.
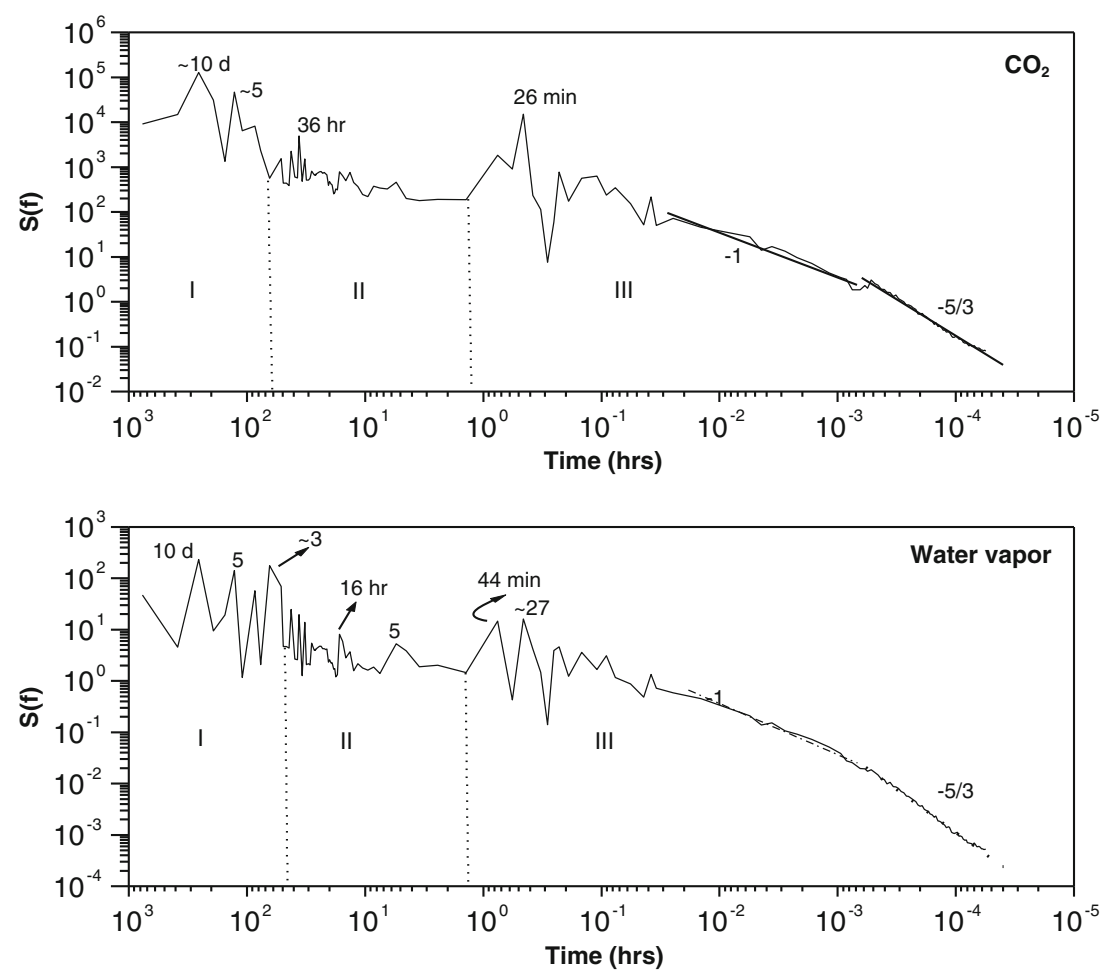

Figure 7. Composite power spectrum of $\mathrm{CO}_{2}$ and water vapour for different scales of motion in the surface layer. 
by the following procedure to form the different time series:

(i) Non-overlapping data series of $1 \mathrm{~s}$ averages.

(ii) Non-overlapping blocks of half hour averaged data points (48 data points per day).

(iii) Conditional sampling of half hour averaged data points at every synoptic hour ( 8 data points per day) over a period of 32 days (August 15-September 15, 2002).

The spectral analysis was performed on the data series (iii) to study the synoptic scale oscillation of $\mathrm{CO}_{2}$ and water vapour. Half hour averages of $\mathrm{CO}_{2}$ and water vapour at every synoptic hour ( 8 samples per day) were used to compute the power spectrum (256 point FFT). Gaps in the data on any day were interpolated with the mean value obtained from available observations on that day. Thus $25 \%$ of missing data were filled during the period.

Similar analysis (512 point FFT) was performed on the half hourly averaged data series (ii) of $\mathrm{CO}_{2}$ and water vapour during the period 15-25 August, 2002. The small scale spectrum of $\mathrm{CO}_{2}$ and water vapour is obtained by performing 8192 point FFT analysis on the continuous data sampled at one second interval (10 samples of raw data averaged) on 7 August 2002 during 1030-1330 IST.

The composite spectrum obtained by combining the above four spectra and their power spectral energy distribution over large, meso, small and micrometeorological scales with corresponding time period (hour) is shown in figure 7. Wherever the spectrum at a particular frequency of a large scale overlaps with the corresponding frequency at the low frequency end of the succeeding spectrum, the corresponding spectral energies were averaged at that frequency to get one single value. Thus, the composite spectrum has been obtained by smoothing the spectral energies corresponding to a given time period (Kaimal and Finnigan 2000).

In the composite spectrum of $\mathrm{CO}_{2}$ and water vapour, three regions can be distinguished representing large (I), meso (II) and small (III) scale motions. Region II depicts a 'spectral gap' around a time period of $1-3$ hours. The corresponding power spectral energy has decreased by two decadal scales $\left(10^{2}-10^{0}\right)$. Similar spectral gap for spectra of wind speed has been shown by Van der Hoven (1957) and Fiedler and Panofsky (1970) which separates the mesoscale contribution from boundary layer scale. The dominant periodicities in the region I are 10 and 5 days. For meso and boundary layer scales the corresponding periodicities are $36 \mathrm{hr}$ and $26 \mathrm{~min}$, respectively. Slope of -1 has been observed in the intermediate range and $-5 / 3$ in the inertial subrange of the micrometeorological spectrum. The periodicities for water vapour in region I are the same as that of
$\mathrm{CO}_{2}$. In meso and small scale regions $\mathrm{S}(\mathrm{f})$ shows prominent periodicities at $16 \mathrm{hrs}, 5 \mathrm{hrs}$ and $44 \mathrm{~min}$, respectively. The dominant mode in micrometeorological scale is $27 \mathrm{~min}$. The spectral gap and -1 power law have been brought out well in figure 7 in the case of both the parameters. During monsoon the large scale motion interacts with small scale motion showing their signatures in the spectrum of scalars $\mathrm{CO}_{2}$ and water vapour as -1 power law.

Spectral distribution pattern in both the spectra are similar. The spectral peak at $\sim 26 \mathrm{~min}$ in the region III (figure 7 ) shows that an averaging time of about 30 min would be sufficient to characterize the variation of $\mathrm{CO}_{2}$ and about 30-45 min that of water vapour in the surface layer.

\section{Conclusion}

Spectral analysis of $\mathrm{CO}_{2}$ and water vapour in the surface layer at Goa during the Indian summer monsoon shows that:

- Magnitude of mean $\mathrm{CO}_{2}$ for the monsoon season was $545-650 \mathrm{mg} \mathrm{m}^{-3}$ which is comparable to the value reported for some coastal stations in Europe.

- For the time scale $<1 \mathrm{hr}$, an inverse relationship of $\mathrm{CO}_{2}$ with water vapour is observed.

- FFT analysis revealed large/synoptic scale oscillations of period 10, 5 days for $\mathrm{CO}_{2}$ and 10, 5 and 3 days for water vapour in the respective power spectrum. The spectral gap (1-3 hours period) followed by -1 power law in the spectrum of $\mathrm{CO}_{2}$ and water vapour suggests that the large scale and small scale motions interact in monsoon season.

- Spectra of $\mathrm{CO}_{2}$ and water vapour obey the Monin-Obukhov scaling. The spectral curve shows the slope of $-5 / 3$ in high frequency portion indicating the existence of inertial subrange. Small scale micrometeorological spectra of $\mathrm{CO}_{2}$ and water vapour depict at the high frequency end the universal Kolmogorov's $-5 / 3$ power law in the inertial subrange.

\section{Acknowledgements}

The authors are grateful to the Director, Indian Institute of Tropical Meteorology, Pune for his keen interest in the experiment and encouragement. They are grateful to the anonymous reviewer for his valuable comments and ideas that helped to improve the manuscript. Authors are grateful to the Department of Science and Technology (DST), Government of India, New Delhi for sponsoring and funding the project ARMEX. 


\section{References}

Abil G and Borges A V 2004 Carbon dioxide and methane emissions from estuaries; In: Green house gases emissions from natural environments and hydro electric reservoirs: Fluxes and processes; Environmental Science Series (eds) Tremblay A, Varfalvy L, Roehm C and Garneau M (New York: Springer), pp. 187-207.

Bacastow R B, Keeling C D and Whorf T P 1985 Seasonal amplitude increase in atmospheric $\mathrm{CO}_{2}$ concentration at Mauna Loa, Hawaii, 1959-1982; J. Geophys. Res. 90(D6) $10,529-10,540$.

Borges A V 2005 Do we have enough pieces of the jigsaw to integrate $\mathrm{CO}_{2}$ fluxes in the coastal ocean?; Estuaries $\mathbf{2 8}$ 3-27, doi: 10.1007/BF02732750.

Borges A V, Delille B and Frank Ignoulle 2005 Budgeting sinks and sources of $\mathrm{CO}_{2}$ in the coastal ocean diversity of eco systems counts; Geophys. Res. Lett. 32 L14601, doi: 10.1029/2005 GL023053.

Borges A V, Schiettecatte L S, Abil G, Delille B and Gazeau F 2006 Carbon di-oxide in European coastal waters; Estuarine Coast. Shelf. Sci. 70 375-387, doi: 10.1016/J.eces.2006.05.046.

Cai W J, Dai J and Wang Y 2006 Air-sea exchange of carbon dioxide in ocean margins: A province-based synthesis; Geophys. Res. Lett. 3312 L12603, doi: 10.1029/2006 GL026219.

Chen C T A and Borges A V 2009 Reconciling opposing views on carbon cycling in the coastal ocean: Continental Shelves as sinks and near-shore ecosystem as sources of atmospheric $\mathrm{CO}_{2}$; Deep-Sea Res. II 56 578590.

Fiedler F and Panofsky H A 1970 Atmospheric scales and spectral gaps; Bull. Am. Meteor. Soc. 51 11141119.

IPCC 2007 Climate Change: Synthesis Report. Contribution of Working Groups I, II and III to the Fourth Assessment Report of the Intergovernmental Panel on Climate Change (eds) Core Writing Team, Pachauri R K and Reisinger A, IPCC (Cambridge: Cambridge University Press), 104p.

Jones E P, Ward T V and Zwick H H 1978 A fast response atmospheric $\mathrm{CO}_{2}$, sensor for eddy correlation flux measurements; Atmos. Environ. 12 845-851.
Jones E P and Smith S D 1977 A first measurement of seaair $\mathrm{CO}_{2}$ flux by eddy correlation; J. Geophys. Res. 82 5990-5992.

Kaimal J C and Finnigan J J 2000 Atmospheric boundary layer flows: Their structure and measurement (NY: Oxford University Press), pp. 269-270.

Leuning R, Denmead D T, Lang A R G and Ohtaki E 1982 Effects of heat and water vapour transport on eddy covariance measurement of $\mathrm{CO}_{2}$ fluxes; Bound. Layer Meteorol. 23 209-222.

Louanchi F, Metzl N and Poisson A 1996 A modelling the monthly sea surface $\mathrm{CO}_{2}$ fields in the Indian Ocean; Marine Chem. 55 265-280.

McNaughton K G and Laubach J 2000 Power spectra and cospectra for wind and scalars in a disturbed surface layer at the base of an advective inversion; Bound. Layer Meteorol. 96 143-185.

Ohtaki E 1985 On the similarity in atmospheric fluctuations of $\mathrm{CO}_{2}$, water vapour and temperature over vegetated fields; Bound. Layer Meteorol. 32 25-37.

Ohtaki E and Matsui M 1982 Infra Red Device for simultaneous measurements of atmospheric $\mathrm{CO}_{2}$ and water vapour; Bound. Layer Meteorol. 24 109-119.

Sarma V V S S, Kumar M D, George M D and Rajendran A 1998 The central and eastern Arabian Sea as a perennial source of atmospheric carbon dioxide; Tellus 50B 2 179-184.

Sirignano C, Neubert R E M, Rödenbeck C and Meijer H A J 2010 Atmospheric oxygen and carbon dioxide observations from two European coastal stations 2000-2005: Continental influence, trend changes and APO climatology; Atmos. Chem. Phys. 10 1599-1615.

Sturm P, Leuenberger M and Schmidt M 2005 Atmospheric $\mathrm{O}_{2}, \mathrm{CO}_{2}$ and $\delta^{13} \mathrm{C}$ observations from the remote sites Jungfraujoch, Switzerland, and Puy de Dôme, France; Geophys. Res. Lett. 32 L17811, doi: 10.1029/ 2005GL023304.

Takahashi T 1989 The carbon dioxide puzzle; Oceanus 32 $22-29$.

Tans P P, Fung I Y and Takahashi T 1990 Observational constraints on the global atmospheric $\mathrm{CO}_{2}$ budget; Science 247 1431-1438.

Van der Hoven I 1957 Power spectrum of horizontal wind speed in the frequency range from 0.0007 to 900 cycles per hour; J. Meteorol. 14 160-164. 